\title{
STEADY-STATE CREEP DEFORMATION OF INVESTMENT CAST NEAR-GAMMA TITANIUM ALUMINIDE
}

\author{
D.A. Wheeler, B. London, and D.E. Larsen, Jr. \\ Howmet Corporation \\ 1500 South Warner St. \\ Whitehall, MI 49461
}

\begin{abstract}
Introduction
The ongoing search for increased aircraft engine performance has prompted the materials community to investigate intermetallic compounds as potential replacement materials for nickel- and cobalt-based superalloys. Of particular interest over the past decade has been near-gamma titanium aluminides due to their low density, high modulus and strength retention at elevated temperatures, and good environmental resistance $(1,2)$. While many investigators have studied the microstructure/property relationships of gamma alloys, only a limited amount of work has been performed on their creep behavior (2-4). Since gamma titanium aluminides have been targeted for use at temperatures approaching $875^{\circ} \mathrm{C}$, it is clearly important to understand their elevated temperature deformation characteristics.
\end{abstract}

The vast majority of creep studies performed to date have concentrated on alloy systems prepared by wrought or powder metallurgy techniques (5-11). However, recent developments have identified investment casting as a viable method for producing complex, near-net shape gamma titanium aluminide components (12-15). As such, the need to examine the creep behavior of these alloys in the cast product form has prompted the current investigation. The stress dependency and activation energy for steady-state creep deformation were determined for cast, near-gamma alloy $\mathrm{Ti}-48 \mathrm{Al}-2 \mathrm{Nb}-2 \mathrm{Cr}$ (at.\%). Post-test microscopy also was performed to characterize the microstructural evolution in these materials after prolonged high temperature exposure. The results are discussed with respect to potential creep deformation mechanisms operating within gamma titanium aluminides.

\section{Experimental Procedure}

The material for this study was produced by Vacuum Arc Remelting (VAR) and casting into $1.6 \mathrm{~cm}$ diameter $\times 15.2 \mathrm{~cm}$ test bars. Following casting, the material was hot isostatically pressed at $1260^{\circ} \mathrm{C} / 172 \mathrm{MPa}$ for 4 hours. The measured chemistry of the castings is given in Table $\mathrm{I}$. Subsequent inert atmosphere heat ireatment at $1350^{\circ} \mathrm{C} / 0.5 \mathrm{~h} / 1300^{\circ} \mathrm{C} / 10 \mathrm{~h} / \mathrm{gas}$ fan $\mathrm{cool}\left(83^{\circ} \mathrm{C} / \mathrm{min}\right)$ produced the duplex microstructure of equiaxed gamma grains within a lamellar (alpha-2/gamma) matrix shown in 
Figure 1. This metallographic section was taken from the grip section of a deformed creep specimen, thereby revealing the stability of the microstructure at the test temperatures. However, a few curved lamellae are observed to result from the longterm elevated temperature exposure. The duplex microstructure was chosen for study because of its overall balance of strength, ductility, and fracture toughness $(11,12,16)$. The test bars were then low-stress ground into $0.51 \mathrm{~cm}$ diameter $\times 2.54 \mathrm{~cm}$ gage length creep specimens.

Creep testing was performed in air using constant load creep frames at $705^{\circ} \mathrm{C}, 760^{\circ} \mathrm{C}$, and $815^{\circ} \mathrm{C}$. Specimen elongation was monitored as a function of time by an linear voltage displacement transducer (LVDT) attached to the specimen grips. To maximize the amount of creep rate information obtained during this study, stress jump testing was employed. Initial specimen loadings were $103 \mathrm{MPa}$ and $138 \mathrm{MPa}$, with a stress jump interval of $69 \mathrm{MPa}$ applied to each specimen after a minimum of 100 hours of steady-state creep deformation. This type of uploading continued until specimen failure. After testing, longitudinal cross-sections taken from the deformed specimen gage lengths were metallographically examined.

\section{Results and Discussion}

The steady-state creep rates plotted in Figure 2 revealed a unique power-law behavior within the stress regime tested. A distinct change in stress exponent from $\mathrm{n}=3$ at low stresses to $\mathrm{n}=7$ at higher stresses is observed, indicating a change in the controlling creep deformation mechanism. The stress exponents measured here are not characteristic of stress-assisted diffusional creep processes, such as NabarroHerring or Coble creep where $n=1$, or dislocation creep processes, where $n=5$. However, recent work has shown that stress exponents can be increased by a factor of 2 when pipe diffusion is rate-controlling during intermediate temperature creep deformation $(17,18)$. With this knowledge, the power-law behavior identified here is possibly explained by diffusional creep at low stresses with a change to dislocation creep at high stresses, both of which being controlled by diffusion via dislocation pipes. This hypothesis is supported by the observation of dislocation alignment and subgrain formation during the creep deformation of gamma alloys $(19,20)$.

An Arrhenius plot of the data, shown in Figure 3, indicates that the activation energy for steady-state creep deformation, Qact, is approximately $300 \mathrm{~kJ} / \mathrm{mole}$. While this value is in agreement with previous measurements $(8-10)$, it is nearly double the measured activation energy for interdiffusion in single phase gamma titanium aluminide (21). The energies required for dislocation nucleation and alignment into subgrains during creep deformation are possible contributors to this high measured activation energy. Of additional interest is the apparent increase in Qact to greater than $400 \mathrm{~kJ} / \mathrm{mole}$ at high stress levels. This observation is consistent with the idea of a change in controlling creep mechanism at higher stress levels, but the details that might cause such an increase remain unknown at this time.

Figure 4 shows that significant dynamic recrystallization has occurred in the gage sections of specimens creep-tested to failure at $815^{\circ} \mathrm{C}$. It is interesting to note the tendency for the recrystallized grains to nucleate along prior grain boundaries of the 
initial microstructure. This tendency indicates that grain boundary sliding also could be playing a role in the deformation process, since the degree of recrystallization is known to be a function of local plastic strain $(22,23)$. Similar examination of specimens deformed at $760^{\circ} \mathrm{C}$ revealed very little, if any, evidence of dynamic recrystallization, even at high stress levels. However, two important points must be noted. First, the above results were obtained solely with the use of light optical microscopy. Further examination of these specimens at higher magnification using transmission electron microscopy could possibly reveal the presence of recrystallized grains at lower test temperatures than determined above. Secondly, all of the specimens examined in this study experienced approximately $10 \%$ uniform plastic elongation prior to the onset of tertiary creep. Since recrystallization is a function of both temperature and stored strain energy, the critical temperature for dynamic recrystallization at lower plastic strains is likely to be somewhat higher.

\section{Conclusions}

The steady-state creep deformation of investment cast gamma titanium aluminide revealed a unique power-law behavior at intermediate temperature and stress levels. The results suggest that dislocation pipe diffusion is controlling a stress-assisted diffusional creep mechanism at low stresses and a dislocation creep mechanism at high stresses. However, the measured activation energy for creep deformation was greater than that required for interdiffusion within single phase gamma, indicating that creep in these alloys may not be explained by intrinsic diffusional processes alone. Dynamic recrystallization was observed along prior grain boundaries of the starting microstructure only in specimens deformed at the highest temperatures. The results of this study suggest that the mechanism(s) of creep deformation in cast gamma titanium aluminides is a complex process which depends strongly on the specific stress and temperature regime being examined.

\section{Acknowledgements}

This work was supported by Howmet Corporation internal research and development funds. The authors gratefully acknowledge helpful discussions with Dr. H.A. Lipsitt of Wright State University and Dr. T. Bieler of Michigan State University during the course of this work.

\section{References}

1) H.A. Lipsitt, High Temperature Ordered Intermetallic Alloys, MRS, 39, pg. 351, (1985)

2) Y.W. Kim and D.M. Dimiduk, JOM, 8, pg. 40, (1991)

3 ) J.M. Larsen, K.A. Williams, S.J. Balsone, and M.A. Stucke, High Temperature Aluminides and Intermetallics, TMS, S.H. Whang, C.T. Liu, D.P. Pope and J.O. Stiegler, eds., pg. 521, (1990)

4) Y-W. Kim and F.H. Froes, High Temperature Aluminides and Intermetallics, TMS, S.H. Whang, C.T. Liu, D.P. Pope and J.O. Steigler, eds., pg. 465, (1990)

5) M.J. Blackburn and M.P. Smith, AFWAL Technical Report \# AFWAL-TR-82-4086, Wright Patterson Air Force Base, OH, (1982) 
6) T. Takahashi and H. Oikawa, Intermetallic Compounds - Structure and Mechanical Properties, JIMIS-6, O. Izumi, ed., pg. 513, (1991)

7) H. Oikawa, High Temperature Aluminides and Intermetallics, TMS, S.H. Whang, C.T. Liu, D.P. Pope and J.O. Steigler, eds., pg. 353, (1990)

8 ) D.S. Shih, S-C. Huang, G.K. Scarr, H.Jang, and J.C. Chesnutt, Microstructure/Property Relationships in Titanium Aluminides and Alloys, TMS, Y-W. Kim and R.R. Boyer, eds., pg. 135, (1991)

9) P.L Martin, M.G. Mendiratta and H.A. Lipsitt, Met. Trans. A, 14A, pg. 2170, (1983)

10) S.L. Kampe, J.D. Bryant and L. Christodoulou, Met. Trans. A, 22A, pg. 447, (1991)

11) S.C. Huang, D.W. McKee, D.S. Shih and J.C. Chesnutt, Intermetallic Compounds Structure and Mechanical Properties, JIMIS-6, O. Izumi, ed., pg. 363, (1991)

12) B. London and T.J. Kelly, Microstructure/Property Relationships in Titanium Aluminides and Alloys, TMS, Y-W. Kim and R.R. Boyer, eds., pg. 285, (1991)

13) S. Sen and D.M. Stefanescu, JOM, 5, pg. 30, (1991)

14) D.S. Reed, Industrial Heating, 1, pg. 20, (1990)

15) Y. Nishiyama, T. Miyashita, S. Isobe and T. Noda, High Temperature Aluminides and Intermetallics, TMS, S.H. Whang, C.T. Liu, D.P. Pope and J.O. Steigler, eds., pg. 557, (1990)

16) S.L. Kampe, P. Sadler, D.E. Larsen and L. Christodoulou, Microstructure/Property Relationships in Titanium Aluminides and Alloys, TMS, Y-W. Kim and R.R. Boyer, eds., pg. 313, (1991)

17) O.A. Ruano, A.K. Miller and O.D. Sherby, Materials Science and Engineering, 51, pg. 9, (1981)

18) S.L. Robinson and O.D. Sherby, Acta Met., 17, pg. 109, (1969)

19) H.A. Lipsitt, D. Shechtman and R.E. Schafrik, Met. Trans. A., 6A, pg. 1991, (1975)

20) M. Koo, T. Matsuo and M. Kikuchi, Intermetallic Compounds - Structure and Mechanical Properties, JIMIS-6, O. Izumi, ed., pg. 519, (1991)

21) K. Ouchi, Y. lijima and K. Hirano, Titanium ' 80 - Science and Technology, TMS, pg. 559, (1980)

22) S. Krishnamurthy and Y-W. Kim, Microstructure/Property Relationships in Titanium Aluminides and Alloys, TMS, Y-W. Kim and R.R. Boyer, eds., pg.149, (1991)

23) H. Chuanzi, L. Mingqiang, L. Tao, D. Jinjun and W. Wentao, Intermetallic Compounds - Structure and Mechanical Properties, JIMIS-6, O. Izumi, ed., pg. 469, (1991)

TABLE I: Chemistry of Cast Test Material

\begin{tabular}{lcccccccc} 
& \multicolumn{8}{c}{$($ wt.\%) } \\
Target & $\mathrm{Ti}$ & $\mathrm{Al}$ & $\mathrm{Nb}$ & $\mathrm{Cr}$ & $\mathrm{Fe}$ & $\mathrm{Si}$ & $\mathrm{Cu}$ & \multicolumn{1}{c}{$\mathrm{Cu}$} \\
\cline { 2 - 10 } & $\mathrm{Bal}$ & 33.34 & 4.78 & 2.68 & $<0.10$ & $<0.10$ & $<0.10$ & $<0.080$ \\
Measured & $\mathrm{Bal}$ & 33.43 & 4.58 & 2.75 & 0.07 & 0.02 & $<0.01$ & 0.055
\end{tabular}




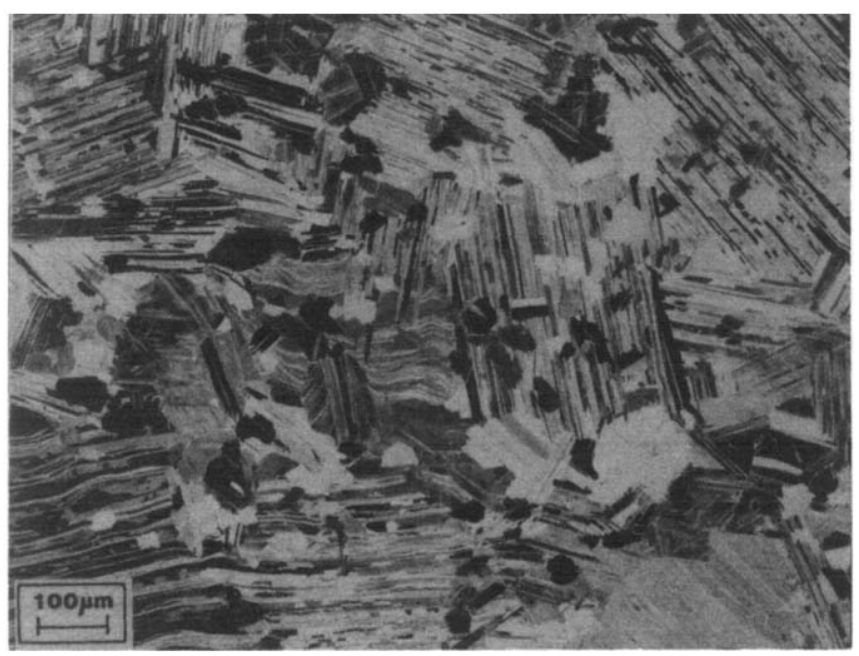

Figure 1: Duplex Microstructure Following Heat Treatment at $1350^{\circ} \mathrm{C} / 0.5 \mathrm{~h} / 1300^{\circ} \mathrm{C} / 10 \mathrm{~h} / \mathrm{GFC}$

\section{Steady State} Creep Rate $10^{\circ}$ $\left(s^{-1}\right)$

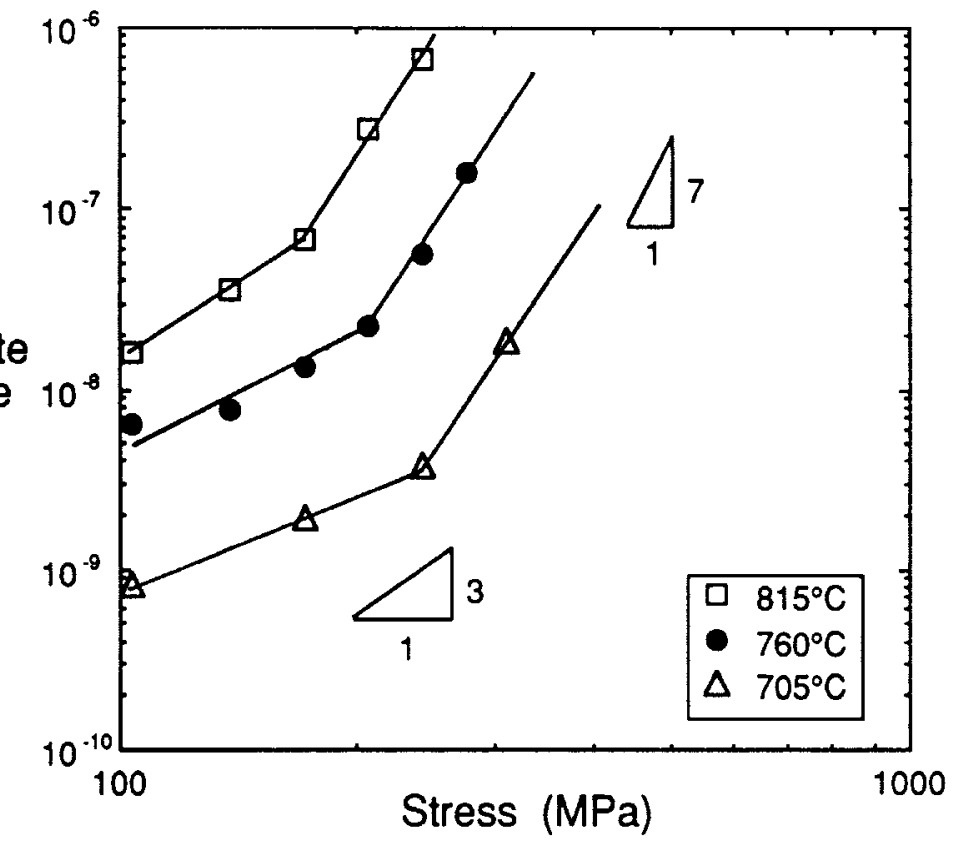

Figure 2: Power-Law Creep Behavior of Cast Ti-48Al-2Nb-2Cr (at\%) 


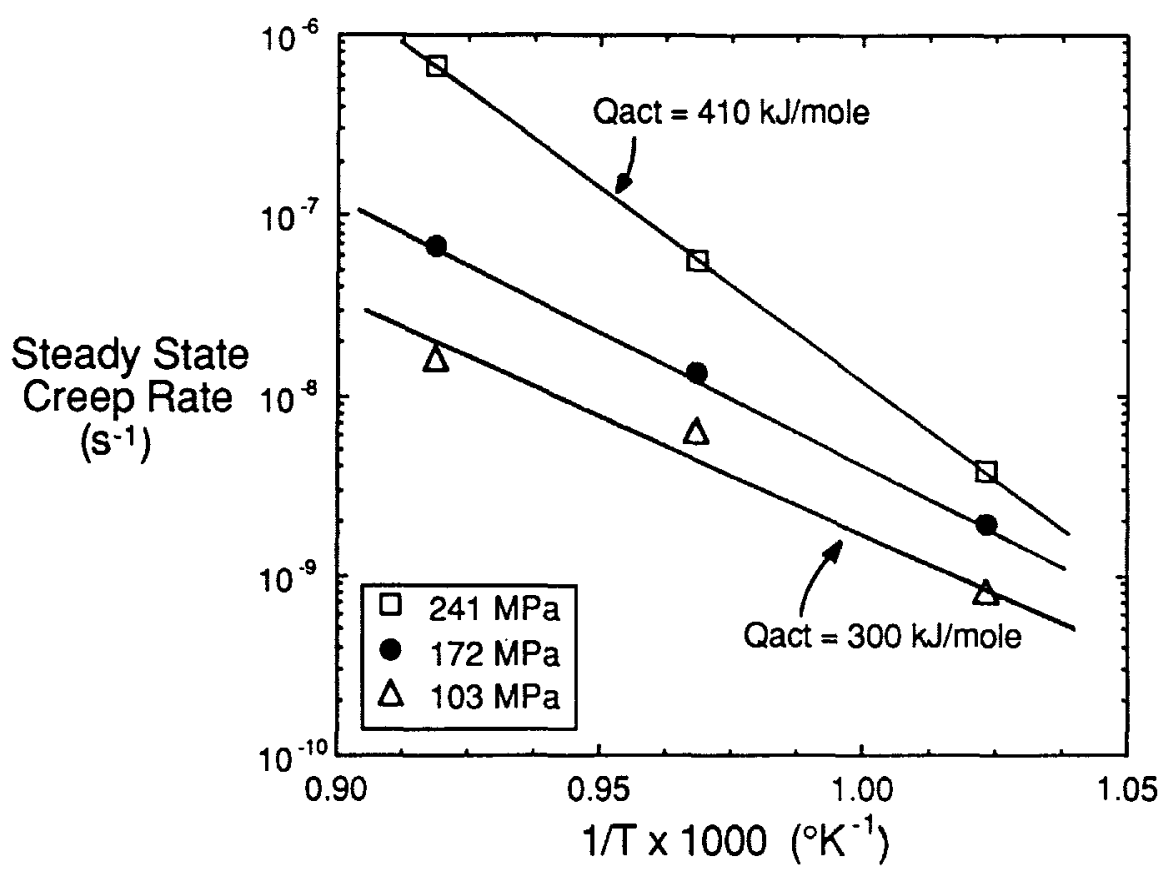

Figure 3: Arrhenius Plot of Cast $\mathrm{Ti}-48 \mathrm{Al}-2 \mathrm{Nb}-2 \mathrm{Cr}$ (at\%)



Figure 4: Dynamic Recrystallization in Gage Section of Creep Specimen after Testing to Failure at $815^{\circ} \mathrm{C}$ 